\section{Exploring the impact of trust and world view on Indigenous patients' engagement in shared decision making}

he relationship between Indigenous populations in Canada engage with the people (i.e. First Nations, Métis and Inuit) and Europeans living in Canta has con Enuously evolved and friendship tring a number of peace agreements, militany other pacts between them. In the late 1800s, however, a series of government regulations related to Indigenous ident sparked tensions and contributed to the Indigenous population's genera distrust of institutions, including healthcare providers.

In Canada, Indigenous peoples are diagnosed with common cancers at a higher rate. They are also more likely to be diagnosed at a later stage and have lower chances of surviving the disease than non-Indigenous people. This could partly be due to their distrust of institutions and their general world view, Inch can differ greaty

Dr Gary Groot and other researchers at the University of Saskatchewan have been conducting extensive research aimed at understanding how trust and world view
affect the extent to which Indigenous

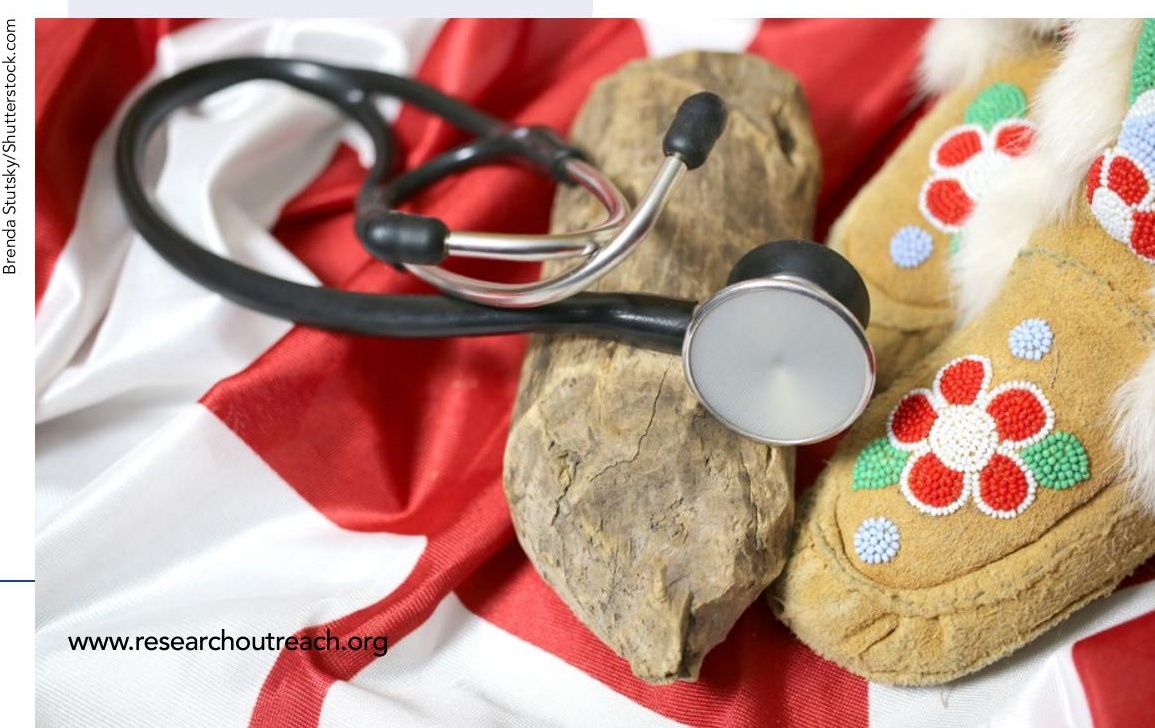
hoalhcare system and with what is known work relied heavily on the contribution Indigenous scholars, who collaborated in several aspects of the research.

\section{THE MODEL OF SHARED} DECISION MAKING

-making mode that became widespread in the late 1980s. This model essentially emphasises the communication and collaboration between healthcare providers, clinicians and patients when making decisions relted to a prient's health, treatment and recovery.

The SDM model consists of several key elements, which it identifies as essentia for a constructive decision-making process. For instance, it suggests that veny least involve a patient and his/her balanced relationship between these parties. Moreover, this process should be based on an open exchange of information (e.g. touching on a patients

The SDM model has proved to be particularly valuable in situations where a she is diagnosed with cancer. In fact, cancer diagnoses generally require patints to make impoltant decisions of information available to them.

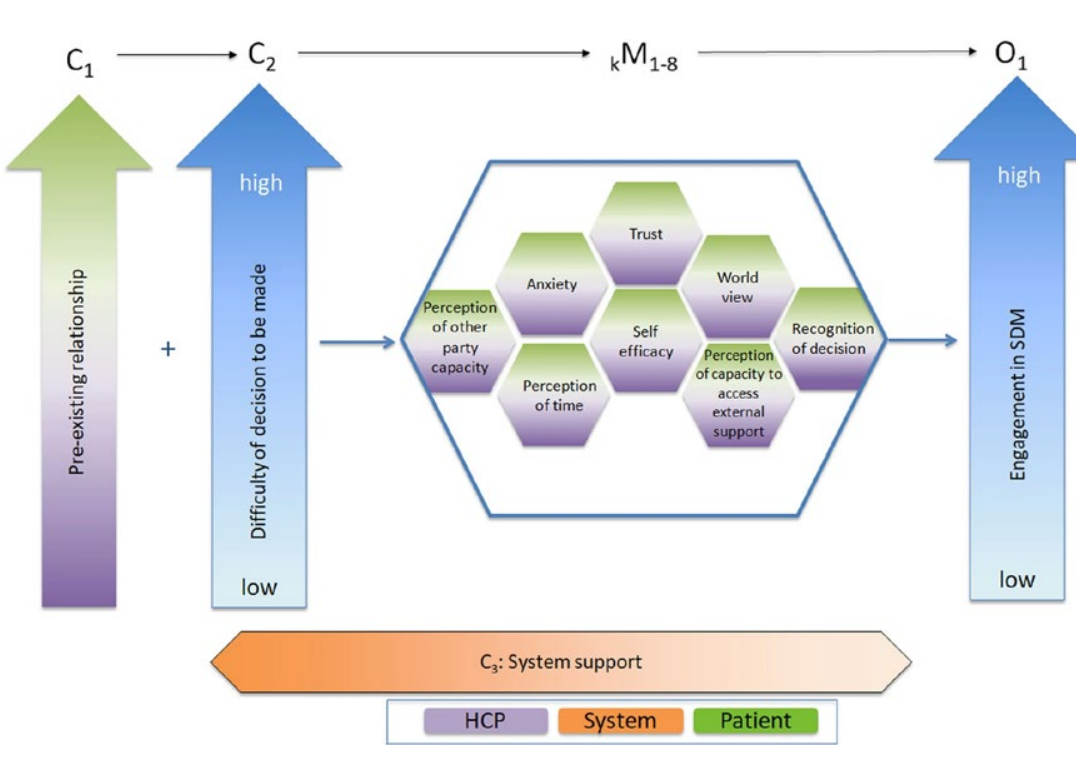
as shared decision making (SDM). Their physician and that it should promote values and preferences) and the discussion
of possible treatment options, leading to a decision that parties mutually agree on. a patient can choose between numerous contexts (C), mechanisms (M) and that could help to shed light on the
Figure 1. Original programme theory of shared decision making.

In their recent studies, Dr Groot and his ome of the factors that might influence whether Indigenous patients engage in SDM with their doctors and local healthcare providers.

WHICH FACTORS INFLUENCE THE DECISIONS OF INDIGENOUS PEOPLES?

"Indigenous peoples have been to colonial forces that have affected their levels of trust with institutions, and at the same time, they have a world view that tends to be distinct from that of non-Indigenous people , Dr Groot explained. "We built on our theory for SDM to understan how trust and work differently for Indigenous patients when engaging in when engaging in

Dr Groot and ew influence patient engagement ver outcomes $(\mathrm{O})$ are extracted from exis literature and configured into realist explanations of why how, and for whom an outcome occurs (i.e. if processes appear (M) in the conditions (C), then given outcome (O) will result)."

\section{REVIEWING PREVIOUS}

OBSERVATIONS

In a study carried out in 2019, Dr Groot and his colleagues screened research

data extracted from a number of online then synthesised these 518 relationships theory of SDM.

The contexts identified by the researchers included patient demographics, the digenous world view, the Canadian healthcare system, institutional support language barriers, and the abuse or discrimination experienced by Indigenous populations throughout history.

Mechanisms involved in SDM, on the other hand, included reciprocal respect between patients and healthcare providers, a patient's perception of whether his/her world views are accepted, and culturally appropriate translations of medical knowledge/mformation. These level of trust in helth the anxiety experienced by Indigenous patients, which ultimately detemined their level of engagement in SDM.

A MORE REALISTIC SDM THEORY CMO configurations they identified to develop a realist synthesis of SDM between Indigenous patients and healthcare providers. Using this synthesis, they then developed a program theory of SDM that outlines a number of core contexts and mechanisms, with a single

improve the healthcare experiences and

Dr Groot developed a realist Indigenous people in synthesis of shared decision making between Indigenous patients and Canada. healthcare providers.

their colleagues wanted to gain a better understanding of how trust and world view perceptions influenced the of Indigenous patients in health-related SDM. To do this, partyed on elements that could partly explain the differences in SDM engagement between Indigenous and non-Indigenous patients.

"In a healthcare consultation involving Indigenous patients, we wanted to explore for whom, why and in what the University of Saskatchewan's iPortal. This included a total of 90 documents, 53 of which were peer-reviewed papers and 37 of which were based on grey literature (i.e. research material produced by organisations outside of traditional publishing and distribution channels).

In these documents, the researchers were able to identify 518 contextmechanism-outcome (CMO) relationsh factors influencing indigenous patient' researchers' theory

are the pre-existing are the pre-existing
relationship between a patient and healthcare providers/ a stitutions, the difficulty of the decisions sey are asked to make, and the suppo ed from the healthcare system. include their anxiety, trust, perception of the other party's competence, perception of time, selfefficacy, world view, perception of capacity of externa decision to mach decision to be made. Finally, the outcom is a patient's 1 .
SDM process. 


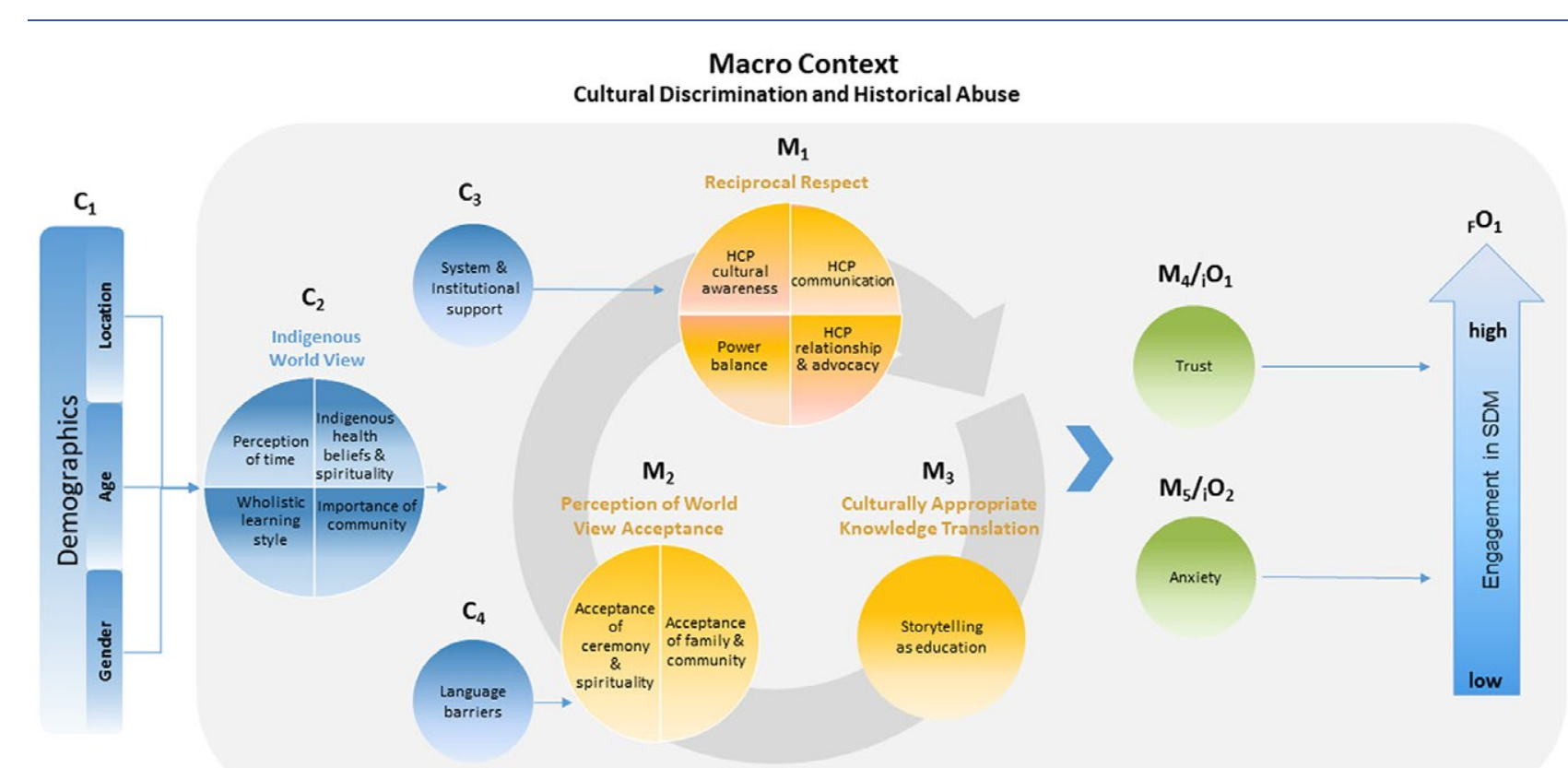

\section{Behind the Research}

\section{Dr Gary Groot}

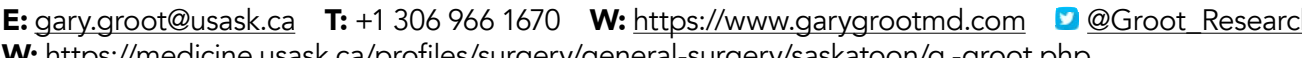
W: https://medicine.usask.ca/profiles/surgery/general-surgery/saskatoon/g.-groot.php

Figure 2. Revised program theory for Indigenous patients.

FACTORS INFLUENCING INDIGENOUS PEOPLE'S CANCER CARE DECISIONS

In another recent study, Dr Groot and his colleagues investigated treatment decision-making processes among Indigenous patients diagnosed with cancer in rural and remote areas in Alberta and Saskatchewan. To do this, they analysed clinical data related to 17 Indigenous cancer patients and discussed it with the patients in question, to ensure that they accurately interpreted their decision-making processes. Transcripts of the interviews with the patients were analysed using a na hative method (i.e. presenting the data in a story-like format.

Dr Groot and his colleagues created eight vignettes summarising some of the main being strong for family, family support, strength and independence, denial and fear-based decision-making, finding the blessing, the patient's spiritual journey, and traditional medicine. This narrative analysis allowed the researchers to unveil similarities and differences in how Indigenous people with cancer decide what treatment to choose.

As part of another study published last year Dr Groot and his colleagues interviewed 14 Indigenous patients diagnosed with cancer utilising a traditional approach to group discussions

were asked to share aspects of their cancer journeys and their experiences while sitting in a 'sharing circle'.

The researchers identified two recurring meta themes in the experiences shared by these patients, namely trust and world view. Trust was represented by mistrust in Western diagnoses and treatments, as well as the protection of Indigenous medicine and expertise. The patients' world views, on the other hand, were characterised by their willingness to combine the best of Indigenous and Western worlds, their spiritual beliefs, the feeling that they should be strong for heir fanily, and heir

traditional Indigenous medicine, others also sought the support of Western healthcare providers. These findings highlight the possible benefits of healthcare systems that allow Indigenous patients to access both traditional and Western medicine.

The collaboration of Indigenous patient partners was of vital importance for these researchers work, as it is what ultimately allowed them to better understand the factors underpinning Indigenous experiences with healthcare services. "Without Wheir support ayd guidance, the initial

\section{Indigenous patients' trust in healthcare} providers and their world view can influence their cancer journeys in unique and complex ways.
TOWARDS A GREATER ENGAGEMENT OF INDIGENOUS PATIENTS IN SDM

Overall, the research carried out by Dr Groot and his colleagues suggests that Indigenous patients' trust in healthcare providers and their world view can prence their cancer journeys in uniqu and complex ways.

The researchers found that while some Indigenous patients only trusted the trust/world piece could not have happened", Dr Groot says.

In the future, the observations gathered by Dr Groot and his research group and the new program theory they devised could inform the work of both clinicians and policymakers in Canada, allowing them to devise strategies to improve the healthcare services offered to Indigenous peoples and to encourage them to make
Research Objectives

Prof Groot explores how trust and perceptions of world view influence patient engagement of Indigenous peoples, aming to improve shared decision making.

\section{Detail}

Address

Room 3242, Health Sciences Building E Wing 107 Wiggins Rd. Saskatoon, SK, S7N 5E5

Canada

Bio

Dr Gary Groot holds a cross-appointment as Associate Professor in the Department of Community Health and Epidemiology and Clinical Professor, Division of General Surgery at the University of Saskatchewan. As the Saskatchewan Health Authority's Clinical Excellence physician co-lead, he bridges evolving healthcare system

Funding

Helth Research Foundation (SHRF) - Saskatchewan Centre for Patient-Oriented Research (SCPOR)

- Canadian Institutes of Health Research (CIHR)

UNIVERSITY OF SASKATCHEWAN

\section{References}

Carr, T., Arcand, L., Roberts, R., Sedgewick, J., Ali, A., Groot, $G$. (2020). The experiences of Indigenous people with cancer in Saskatchewan. a patient-oriented qualitative study using a sharing circle. CMAJ OPEN, 8(4), E852-E859. Available at https://doi.org/10.9778/cmajo.20200012

Groot, G., Waldron, T., Barreno, L., Cochran, D., Carr, T. (2019). Trust and world view in shared decision making with in org/10.1111/jep.13307

Roberts, R.A., Groot, G., Carr, T. (2020). Decisions on cancer care by Indigenous peoples in Alberta and Saskatchewan: Available at: https://doi.org/10.22605/RRH5610

Waldron, T., Carr, T., McMullen, L., Westhorp, G., Duncan, V. Neufeld, S.M., Bandura, L.A., Groot, G. (2020). Development of a program theory for shared decision-making: a realist synthesis. BMC Health Services Research, 20(59), 1-17. Available at: https://doi.org/10.1186/s12913-019-4649-1

\section{Personal Response}

What inspired you to conduct this research?

II Caring for cancer patients requires excellent

technical, cognitive and social skills, inclualing the ability to undaining the risks and benefits of the options available to them. What began as a journey to improve my person communication skills with Indigenous cancer patients quickly evolved into an understanding that engaging Indigenous patients in a shared decision-making process is of a more comprehensive and collaborative exploration with Indigenous patients and Indigenous scholars. When the opportunity to research this topic presented itself, I
gratefully took advantage of it. 